\title{
CHLORIDE EXCRETION DURING GLYCOSURIA IN PATIENTS WITH DIABETES
}

\author{
By J. L. GABRILOVE 1 \\ (From the Department of Medicine, Yale University School of Medicine, and the Medical \\ Service of the New Haven Hospital)
}

(Received for publication November 29, 1945)

Diabetic patients with acidosis and coma commonly are markedly depleted of extracellular salt (1). This is often due, in part at least, to the persistent vomiting which frequently accompanies diabetic acidosis. It has been suggested, however, that the excessive glycosuria which regularly precedes the development of acidosis might contribute to this salt depletion by favoring an excessive preliminary salt excretion (2) in the urine. Glycosuria might produce salt depletion in two ways: $(a)$ in the absence of an adequate fluid intake, the obligatory excretion of water necessary for the urinary excretion of glucose may result in a deficit of body water; under some circumstances this may be followed by a secondary depletion of the body stores of salt: (b) glycosuria per se is said to accelerate the excretion of sodium chloride, even though water depletion is avoided (3). Except in the presence of nausea or vomiting there is no reason for the fluid intake of the diabetic to be inadequate. Consequently it is a matter of particular importance to determine whether, in the presence of an adequate intake of food and fluid, glycosuria directly accelerates the urinary excretion of sodium chloride and thereby favors salt depletion.

\section{PLAN OF STUDY}

Diabetic patients on the wards of the hospital were studied. They had been admitted originally for various complaints, for the most part referable to complications of their underlying diabetic status, which required some days of hospitalization. Patients with evidence of renal disease or of heart failure were excluded. Each patient was placed on a weighed "salt-free" hospital diet, prepared in the diet kitchen. No attempt was made to remove the salt in the food, but no salt was employed in the preparation or serving of the diet. Typical diets of this type contain from 2 to 4

\footnotetext{
1 Emanuel Libman Fellow.
}

grams of sodium chloride daily, depending largely upon the caloric value of the diet. Some patients were given supplementary sodium chloride in the form of salt tablets.

During a control period of several days an attempt was made to prevent glycosuria. Each total 24-hour urine specimen was analyzed for chloride and glucose. After the daily chloride excretion had been stabilized, glycosuria was induced by means of the intravenous or oral administration of carbohydrate, by the withdrawal of insulin, or by a combination of these procedures. Collection and chemical analyses of the serial total 24-hour urine specimens were continued during the period of glycosuria and for some days thereafter. From time to time blood serum was obtained for chloride analysis. Qualitative acetone tests were performed to exclude the presence of ketosis.

\section{CHEMICAL METHODS}

Sugar in urine was determined by the technique of Shaffer and Somogyi (4), employing Reagent 50 with one gram of potassium iodide per liter. The urine was diluted either 1 to 100 or 1 to 200 , the latter being employed whenever the Benedict qualitative sugar test showed complete reduction. Yeast fermentation was employed to correct for the non-glucose reducing substance in the urine. Chloride in urine was determined by the Volhard-Harvey (5) titration. Chloride in serum was determined by the Hald micro-modification of the open Carius method (5). Acetone in urine was determined qualitatively by the Lange reaction. All analyses were performed in duplicate.

\section{RESULTS}

Four typical studies are presented in detail (Figure 1:a, b, c, and d) in order to illustrate the findings in all 7 of the patients studied.

Chloride excretion varied considerably with a constant daily intake of chloride during the control period. For example, the daily urinary excretion of chloride varied from 64 to 162 milli- 
equivalents while the patient was receiving about 135 milliequivalents daily.

No significant increase in chloride excretion with glycosuria was noted in 4 experiments in which glycosuria was induced by the intravenous administration of glucose, nor in 1 experiment in which glycosuria was induced by the oral as well as by the intravenous administration of glucose (Figures 1: a, b, and c). Neither did an excessive excretion of chloride follow the increase in glycosuria induced by withdrawal of insulin (Figure 1b) nor was there any association between glycosuria and chloride excretion in another experiment in which insulin dosage was inadequate. One patient receiving a relatively free diet failed to develop salt depletion in spite of persistent marked glycosuria (Figure 1d).

There was no significant (more than 3 milliequivalents) decline in the concentration of chloride in serum following the period of glycosuria in 3 patients studied.

\section{DISCUSSION}

Under the circumstances of these experiments, i.e. a free intake of water, an adequate intake of food, and the absence of ketosis, the daily urinary excretion of chloride was apparently unaffected by the presence or absence of glycosuria. Whether the glycosuria was induced by excessive intake of carbohydrate, or by withdrawal of insulin with consequent reduction in carbohydrate combustion, the result was the same. The experiments, therefore, call into question the theory that glycosuria per se favors urinary salt loss.

The evidence which, in the past, has usually been taken to prove that glycosuria does produce an excessive urinary salt loss in diabetes is derived chiefly from the observations of Atchley and his associates (2). Certain experiments of Hare, Hare and Phillips (6) with normal dogs, and of Kerpel-Fronius with rabbits (7) have been thought to furnish supplementary evidence.

The experiments of Atchley et al. are, however, complicated by ketosis, partial starvation, and restriction to a constant fluid intake in the face of increasing urine volume. The increase in sodium and chloride excretion immediately after the withdrawal of insulin disappeared in two or three days although glycosuria persisted. It is doubtful, therefore, whether they can be attributed to the glycosuria per se.

The experiments of Hare et al. are difficult to interpret since the effects of glycosuria are combined with those of intravenous infusion and water diuresis. They injected 10 per cent glucose intravenously into normal dogs at the rate of 10 ml. per minute. Some chloride loss resulted. However, in other experiments chloride excretion was no greater with the intravenous administration of 10 per cent glucose dissolved in 2 per cent saline than with 2 per cent saline alone. Their experiments do not, therefore, demonstrate a clear cut effect of glycosuria on chloride excretion. In connection with the interpretation of these and other experiments with dogs it should be recalled that phlorizin administration, which produces a severe glycosuria, does not affect the excretion of chloride (8).

In normal rabbits, Kerpel-Fronius (7) produced depletion of the body stores of sodium chloride by the intravenous administration of glucose solutions. The application of these experiments to man is of questionable validity, since the rabbit kidney is peculiarly constituted. In the rabbit variations in rate of urine excretion are effected by changes in renal blood flow and of glomerular filtration, while in man they result from variations in the tubular reabsorption of water. The urinary chloride loss by these rabbits may as well have been associated with the untoward increase in renal blood flow as with the glycosuria itself (8).

In view of the work of Gamble, McKhann, Butler, and Tuthill (9) on the additive effects of salts and glucose, compared on an osmolar basis, on obligatory water excretion by the rat, the data from all 7 of our patients have been analyzed in this light. The amounts of chloride and of glucose excreted daily were converted into osmolar terms, the values added together, and the sum plotted against the corresponding urine volume (Figure 2). Urine volume does vary roughly with the osmolar content. The points are more widely scattered in the lower range of values for urine volume and osmolar content, probably because urine volume is more apt to be determined by its urea content at these lower rates of salt and glucose excretion. As has been shown in the rat (9) urea does not ordinarily compete for water 

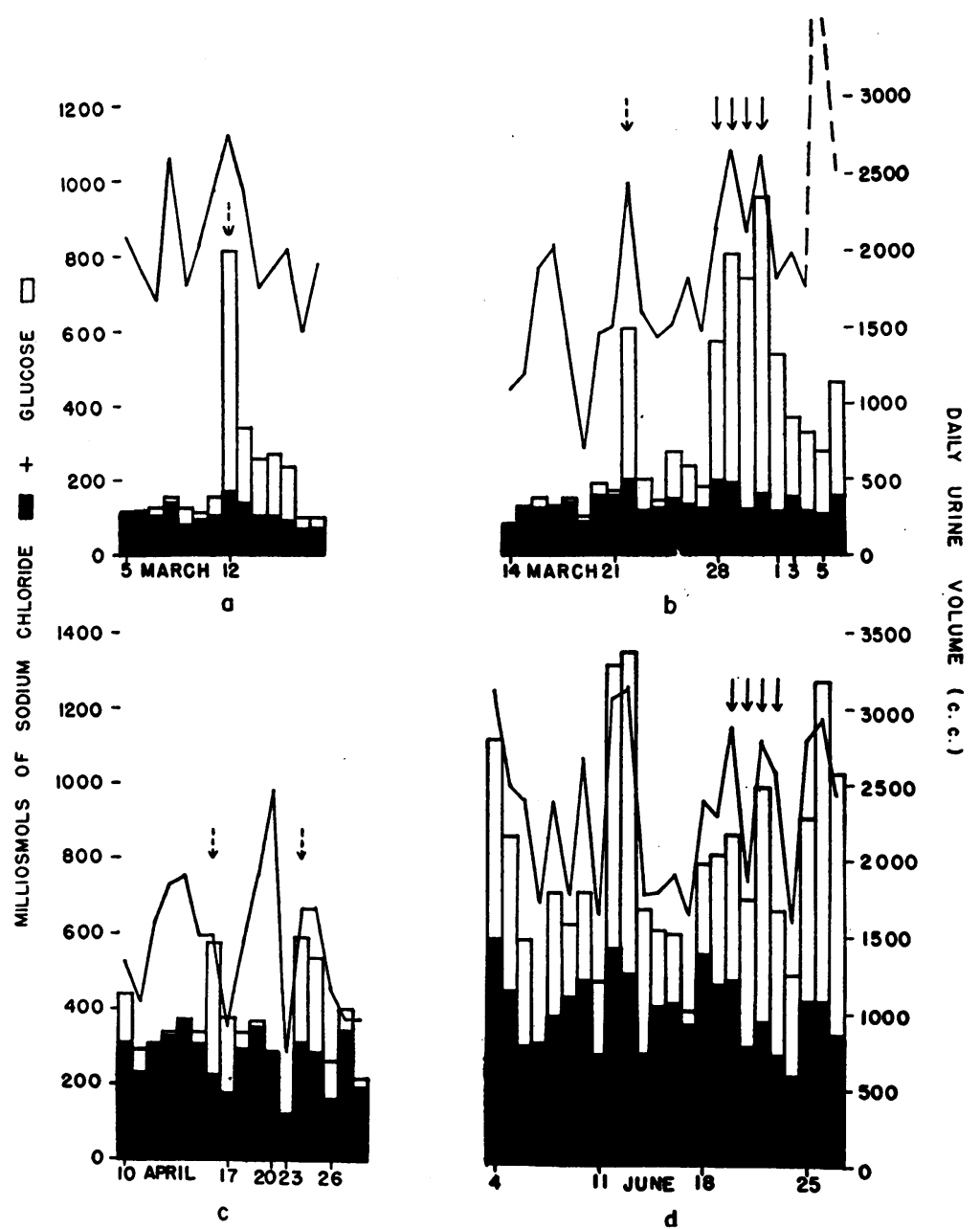

Fig. 1. The Daily Urinary Excretion of Chloride (Solid Blocks) and of Glucose (Open Blocks) Are Plotted Before, During, and After the Induction of Glycosuria by Vartous Means

Fluctuations in the daily volume of urine are indicated by a solid line. Chloride and glucose are expressed in osmolar terms, chloride being expressed in its equivalent of sodium chloride (i.e., twice the milliosmolar value of chloride alone). Each of the 4 divisions (a, b, c, and d) represents a study with a different diabetic patient.

(a) Diet "salt-free," protein 90 grams, fat 150 grams, carbohydrate 200 grams daily. The dotted arrow indicates the intravenous injection of 200 grams of glucose as 50 per cent solution in 4 equal doses at intervals of 4 hours.

(b) Diet "salt-free," protein 80 grams, fat 150 grams, carbohydrate 250 grams daily. On March 19 the full diet was not taken because of incision and drainage of a plantar abscess. Values for April 2 are omitted because the 24-hour urine specimen was lost. On April 5 the urine volume was $4180 \mathrm{ml}$; the large volume resulted from forced administration of large amounts of fluid by mouth. Dotted arrow indicates intravenous administration of glucose as 50 per cent solution in doses of 50,50 ,
50, and 13 grams with 4-hour intervals between doses. The solid arrows indicate the effect of withdrawal of insulin (60 units of regular insulin daily).

(c) Diet "salt-free," 6 grams of $\mathrm{NaCl}$ added; protein 80 grams, fat 130 grams, carbohydrate 250 grams daily. The values for April 21 to 22 were omitted from the figure since the urine of these 2 days was pooled; the average values for 24 hours were: volume $1285 \mathrm{ml}$., glucose 12 milliosmols, $\mathrm{NaCl} 356$ milliosmols. Dotted arrow indicates the intravenous injection of glucose as $\mathbf{5 0}$ per cent solution in equal divided doses at intervals of 4 hours, a total of 200 grams on April 16 and 175 grams on April 24.

(d) Solid arrow indicates the effect of withdrawal of insulin (50 units of protamine zinc insulin and 45 units of crystalline insulin daily). Although insulin was withdrawn for a period of 4 days, no ketosis developed. This behavior contrasts sharply with the previous reaction of this patient to insulin withdrawal. Indeed she had been admitted initially because of ketosis, acidosis, and coma, 


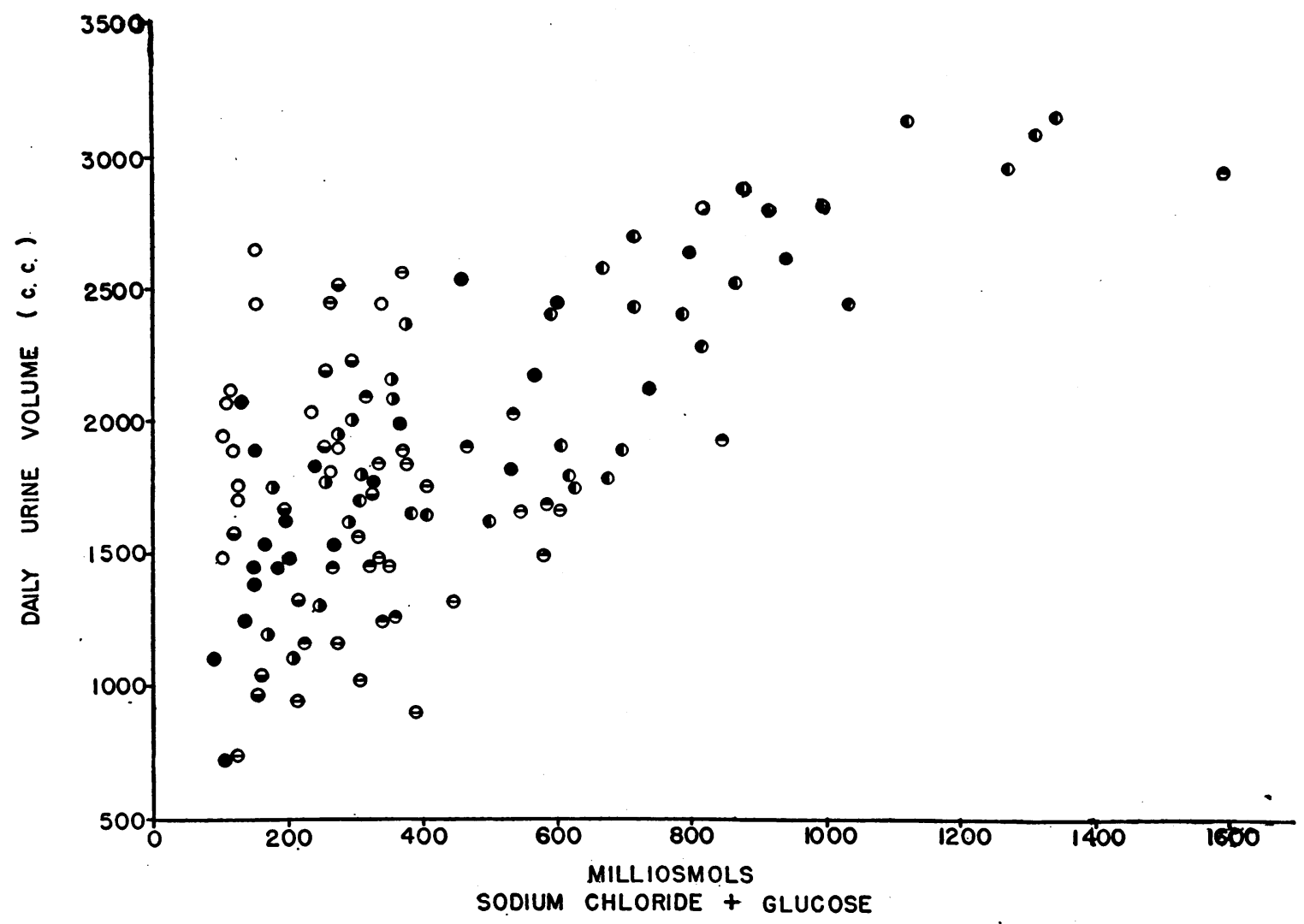

Fig. 2. The Relation of Volume of Each 24-Hour Urine Sample to Its Osmolar Content of Sodium Chloride Plus Glucose

In general there is a rough positive correlation. Each case is represented by a different symbol.

with salt and glucose. Our data suggest that the human kidney behaves toward salt, glucose, and urea in a manner similar to that of the rat. The results are consistent with the theory that the diuresis commonly associated with glycosuria (the "polyuria" of untreated diabetes) is effected by the addition of the osmolar effect of glucose to that of the salt being simultaneously excreted.

These findings indicate that the salt depletion which is so characteristic a feature of severe diabetic acidosis and coma (1) must be due to some cause other than urinary salt loss during the period of severe glycosuria which often precedes the development of ketonemia and ketonuria.

\section{SUMMARY}

Glycosuria per se does not accelerate the urinary excretion of chloride by the diabetic patient without ketosis who is ingesting food and fluid freely.

I am indebted to Dr. John P. Peters and Dr. Alexander W. Winkler for advice and criticism. which had developed after voluntary omission of her usual insulin dosage, during a period in which her dietary intake had been markedly reduced. The difference in behavior may have been due to an inhibition of ketosis by the liberal carbohydrate administration during the 4-day experimental period as well as during the earlier study period.

The dietary intake of this patient is unknown, since in addition to her daily prescribed "salt-free" diet with 6 grams of added $\mathrm{NaCl}$ and 1 gram of choline chloride, containing 90 grams of protein, 175 grams of fat, and 175 grams of carbohydrate, she irregularly ate unprescribed additions to her diet, such as salted crackers. The study demonstrates that no chronic depletion of salt resulted from her marked persistent glycosuria. At first she lost some weight, but later body weight became stabilized. Clinically, hydration always appeared adequate. 


\section{BIBLIOGRAPHY}

1. Peters, J. P., Kydd, D. M., Eisenman, A. J., and Hald, P. M., The nature of diabetic acidosis. J. Clin. Invest., 1933, 12, 377.

2. Atchley, D. W., Loeb, R. F., Richards, D. W., Jr., Benedict, E. M., and Driscoll, M. E., On diabetic acidosis. J. Clin. Invest., 1933, 12, 297.

3. Peters, J. P., Water exchange. Physiol. Rev., 1944, 24, 491.

4. Shaffer, P. A., and Somogyi, M., Copper-iodometric reagents for sugar determination. J. Biol. Chem., 1933, 100, 695.

5. Peters, J. P., and Van Slyke, D. D., Quantitative
Clinical Chemistry. Vol. 2. Williams and Wilkins Co., Baltimore, 1932.

6. Hare, R. S., Hare, K., and Phillips, D. M., The renal excretion of chloride by the normal and by the diabetes insipidus dog. Am. J. Physiol., 1943, 140, 334.

7. Kerpel-Fronius, E., Zur Frage des diabetischen Salzmangelzustandes. Klin. Wchnschr., 1937, 16, 1466.

8. Smith, H. W., The Physiology of the Kidney. Oxford University Press, New York, 1937.

9. Gamble, J. L., McKhann, C. F., Butler, A. M., and Tuthill, E., An economy of water in renal function referable to urea. Am. J. Physiol., 1934, 109, 139. 